\title{
DESEMPENHO AGROINDUSTRIAL DO SORGO SACARINO SUBMETIDO A DIFERENTES DOSES DE NITROGÊNIO E POTÁSSIO EM COBERTURA
}

\author{
JÚNIA DE PAULA LARA ${ }^{1}$, IRAN DIAS BORGES², FLÁVIA CRISTINA DOS SANTOS 3 \\ e RAFAEL AUGUSTO DA COSTA PARRELLA ${ }^{3}$
}

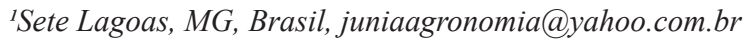

${ }^{2}$ Universidade Federal de São João del-Rei, Campus Sete Lagoas, Sete Lagoas-MG, Brasil, irandb@ufsj.edu.br

${ }^{3}$ Embrapa Milho e Sorgo, Sete Lagoas-MG, Brasil, flavia.santos@embrapa.br, rafael.parrella@embrapa.br

$\overline{\text { Revista Brasileira de Milho e Sorgo, v.17, n.3, p. 474-489, } 2018}$

\begin{abstract}
RESUMO - O sorgo sacarino pode ser plantado para fins energéticos. O objetivo deste trabalho foi avaliar o desempenho agroindustrial, qualitativamente e quantitativamente, da cultivar de sorgo sacarino BRS 511 submetida a diferentes doses de $\mathrm{Ne} \mathrm{K}_{2} \mathrm{O}$ em cobertura. Foi conduzido experimento sem irrigação na região Central de Minas Gerais. O delineamento utilizado foi em blocos casualizados, com 3 repetições, e os tratamentos foram dispostos em esquema fatorial 4x4, sendo 4 doses de nitrogênio $\left(45,90,135\right.$ e $\left.180 \mathrm{~kg} \mathrm{ha}^{-1}\right)$ x 4 de potássio $(50,100,150$ e $200 \mathrm{~kg}$ $\mathrm{ha}^{-1}$ ) em cobertura. Características avaliadas: extração de caldo, massa verde, massa seca, sólidos solúveis totais, ${ }^{\circ}$ Brix t/ha, teor de sacarose, açúcar redutor total, quantidade de álcool por hectare e quantidade de álcool por tonelada de massa verde. $\mathrm{O}$ sorgo sacarino respondeu à adubação nitrogenada e potássica em cobertura, sendo que a adubação nitrogenada interferiu mais nas variáveis analisadas em relação ao potássio. O melhor desempenho considerando a produção de litros de etanol por hectare, toneladas de ${ }^{\circ}$ Brix por hectare, litros de etanol por tonelada de massa verde, teor de sacarose e açúcar redutor total foi obtido com altas doses de $\mathrm{Ne} \mathrm{K}_{2} \mathrm{O}$ em cobertura (cerca de 120 e $130 \mathrm{~kg} \mathrm{ha}^{-1}$, respectivamente).
\end{abstract}

Palavras-chave: etanol, Sorghum bicolor, adubação.

\section{AGROINDUSTRIAL PERFORMANCE OF SORGHUM SACCHARINE SUBJECTED TO DIFFERENT DOSES OF TOPDRESSED NITROGEN AND POTASSIUM}

\begin{abstract}
The sweet sorghum, or sorghum saccharine, is planted in reformed areas of sugarcane for energy purposes. The objective of this study was to assess qualitatively and quantitatively the agroindustrial performance of sorghum saccharine cultivar BRS 511 subjected to different doses of topdressed $\mathrm{N}$ and $\mathrm{K} 2 \mathrm{O}$, without irrigation in the Central region of Minas Gerais. A randomized block design with three replications was used and treatments arranged in a factorial $4 \times 4$ with four nitrogen rates $\left(45,90,135\right.$ and $\left.180 \mathrm{~kg} \mathrm{ha}^{-1}\right)$ and 4 potassium doses $(50,100,150$ and $200 \mathrm{~kg}$ $\left.\mathrm{ha}^{-1}\right)$. The characteristics evaluated were: juice extraction, green mass, dry matter, total soluble solids, tons of Brix per hectare, sugar content, total reducing sugar, alcohol and ethanol per hectare per ton of biomass. The best performance of sorghum saccharine, considering the production of liter of ethanol per hectare, tons brix per hectare, gallons of ethanol per ton of biomass, sugar content and sugar total reducing, occurred with use of high doses of topdressed $\mathrm{N}$ and $\mathrm{K}_{2} \mathrm{O}$ (up to 120 to $130 \mathrm{~kg} \mathrm{ha}^{-1}$, respectively).
\end{abstract}

Keywords: ethanol, Sorghum bicolor, fertilizer. 
A grande preocupação atual com o meio ambiente, as constantes mudanças climáticas e a crise energética fazem com que seja necessário procurar alternativas de fontes de energia limpas e renováveis. Existe atualmente um interesse em pesquisas nestes temas, com a intenção de reduzir o consumo de fontes não renováveis, além de diminuir $90 \%$ da emissão de dióxido de carbono no meio ambiente e gerar emprego no setor rural, consequentemente, promovendo o desenvolvimento em regiões remotas no Brasil (Plano..., 2006). Dentre essas alternativas está o etanol de $1^{\mathrm{a}}$ e de $2^{\mathrm{a}}$ geração, oriundo de culturas como a cana-de-açúcar, o sorgo sacarino e o milho.

Pela sua facilidade de transporte e substituição no consumo da gasolina, o etanol ainda possui a característica de não ser tóxico e ser menos poluente (Ortega et al., 2016). Além disso, alguns países têm o compromisso de cumprir o Protocolo de Kyoto, que preconiza redução do efeito estufa no mundo, e o uso do etanol facilita atingir este objetivo. Diante disso, como matéria-prima disponível e renovável para produção de etanol, destaca-se o sorgo sacarino (Sorghum bicolor (L.) Moench).

A planta de sorgo sacarino representa uma alternativa promissora para a produção de etanol no Brasil, tanto do ponto de vista agronômico quanto industrial, por apresentar colmos suculentos com açúcares fermentáveis. A cultura é plantada entre os meses de outubro e dezembro (dependendo da região produtora) e colhido nos meses de fevereiro a abril para as regiões Sul, Sudeste e Centro-Oeste do Brasil. Nesta época, a colheita coincide com a entressafra da cana-de-açúcar, com isso, o sorgo sacarino pode fornecer matéria-prima de qualidade entre os meses de janeiro e abril, época em que as usinas de beneficiamento da cana ficam ociosas, e a produção de etanol diminui consideravelmente no País. Ademais, o pro- cessamento dos colmos deste tipo de sorgo é o mesmo já utilizado para a cana-de-açúcar, representando uma alternativa importante para plantio em áreas de reforma de canavial, sem a necessidade de ocupação de novas áreas (Durães, 2011).

A produtividade de etanol das cultivares de sorgo sacarino é considerada satisfatória e está associada a suas características agroindustriais, como rendimento de colmos por hectare, umidade da biomassa, ${ }^{\circ}$ Brix no caldo, porcentagens de extração de caldo, fibra dos colmos, açúcar redutor total, as quais irão refletir em litros de etanol por tonelada de colmos (Durães, 2011).

O requerimento nutricional das plantas de sorgo varia diretamente com o potencial de produção, envolvendo também diversas interações entre características de solo, do clima, do sistema de rotação/sucessão de culturas, época de semeio, cultivar, adubação e tratos fitossanitários. O sorgo responde a incrementos no suprimento de água e à adubação, alcançando ou superando, em alguns casos, as produções de massa seca e de grãos normalmente obtidas com a cultura do milho (Durães, 2011). Então, nutrientes como N, P e K, que são requeridos em maior quantidade, influenciam diretamente a produtividade.

No manejo da adubação, entre outros, deve-se atentar para a extração de nutrientes do solo pela planta. O sorgo sacarino é uma cultura que possui alta demanda nutricional para alcançar elevada produtividade. Nesta condição, a cultura extrai e exporta uma grande quantidade dos nutrientes nitrogênio e potássio, em especial (Resende et al., 2009). Essa quantidade é quantificada por Santos et al. (2014) com 14,0;11,1;3,0;2,5;1,3;0,7 $\mathrm{kg} \mathrm{t}^{-1} \mathrm{e}$ 225,0; 26,9; 22,7 e 4,4 $\mathrm{g} \mathrm{t}^{-1}$ de K, N, Ca, Mg, P, S, Fe, $\mathrm{Mn}, \mathrm{Zn}$ e $\mathrm{Cu}$, respectivamente para produção de uma tonelada de massa seca, e confirmada por (Santos et 
al., 2015), que encontraram a extração dos nutrientes primários $\mathrm{N}, \mathrm{P}$ e $\mathrm{K}$ de 11,06; 1,36 e 14,27 $\mathrm{kg} \mathrm{t}^{-1}$ de matéria seca produzida. Segundo os mesmos autores, as pesquisas desenvolvidas pela Embrapa Milho e Sorgo, que identificam essas extrações, sugerem que para produção de colmo de sorgo sacarino, em solos de fertilidade corrigida, maior que $50 \mathrm{t} \mathrm{ha}^{-1}$ deve-se aplicar no plantio $20 \mathrm{~kg} \mathrm{ha}^{-1}$ de N, $180 \mathrm{~kg} \mathrm{ha}^{-1}$ de $\mathrm{P}_{2} \mathrm{O}_{5}$ e $60 \mathrm{~kg} \mathrm{ha}^{-1}$ de $\mathrm{K}_{2} \mathrm{O}$ e em cobertura $160 \mathrm{~kg} \mathrm{ha}^{-1}$ de $\mathrm{N}$ e $140 \mathrm{~kg} \mathrm{ha}^{-1}$ de $\mathrm{K}_{2} \mathrm{O}$ quando as plantas apresentarem de quatro a seis folhas (Santos et al., 2014). Na colheita do sorgo sacarino, a planta inteira é retirada da área, por isso faz-se necessário um monitoramento frequente da fertilidade do solo por causa da alta exportação de nutrientes e estes precisam ser repostos ao solo por meio de adubação, garantido uma constante produtividade.

Quando a planta cresce e se desenvolve, além de aumentar sua matéria verde e seca para proporcionar maior produtividade, é necessário identificar a melhor estratégia de adubação para incremento de parâmetros também correlacionados com a produção industrial. Contudo, ainda existem poucos estudos de recomendação de adubação para a cultura do sorgo sacarino, além de, muitas vezes, esses se basearem na cultura do sorgo forrageiro e até mesmo na cultura do milho, sendo necessário rever e complementar as informações já existentes. Assim, pode-se evidenciar a hipótese de que a adubação em cobertura influencia bastante as características agronômicas e industriais da planta de sorgo sacarino.

Este trabalho teve como objetivo avaliar qualitativamente e quantitativamente o desempenho agronômico e industrial de uma cultivar de sorgo sacarino submetida a diferentes doses de $\mathrm{N}_{\text {e }} \mathrm{K}_{2} \mathrm{O}$ em cobertura, conduzida em sistema de sequeiro na região Central de Minas Gerais.

\section{Material e Métodos}

O trabalho foi conduzido em área experimental da Universidade Federal de São João del-Rei, no campus de Sete Lagoas-MG. A área está localizada em terreno limítrofe a Embrapa Milho e Sorgo com as coordenadas geográficas $19^{\circ} 28^{\prime} 36^{\prime \prime}$ de latitude sul e $44^{\circ} 11^{\prime}$ '53" de longitude oeste, altitude de $769 \mathrm{~m}$. O experimento foi instalado em Latossolo Vermelho Distrófico, com as seguintes características, antes da condução do experimento: $\mathrm{pH}$ em água $=5,8$; P-Mehlich $1=52,04 \mathrm{mg} \mathrm{dm}^{-3} ; \mathrm{H}+\mathrm{Al}=4,41 ; \mathrm{Ca}=5,95$; $\mathrm{Mg}=0,88 ; \mathrm{Al}=0,01 ; \mathrm{SB}=8,24 ; \mathrm{CTC}=12,65\left(\mathrm{cmol}_{\mathrm{c}}\right.$ $\left.\mathrm{dm}^{-3}\right) ; \mathrm{K}=551,2 ; \mathrm{Cu}=0,73 ; \mathrm{Fe}=41,45 ; \mathrm{Mn}=69,72 ; \mathrm{Zn}$ $=4,08\left(\right.$ dag kg-1 $\left.^{-1}\right)$; matéria orgânica $=4,73\left(\right.$ dag $\left.\mathrm{kg}^{-1}\right) ; \mathrm{V}$ $=65,13 \%$; Sat. $\mathrm{Al}=0,12 \%$; carbono $=2,75\left(\right.$ dag $\left.\mathrm{kg}^{-1}\right)$.

O clima local segundo Köppen (Ometto, 1981) é do tipo AW (tropical estacional de savana, inverno seco), temperatura média anual $22,1{ }^{\circ} \mathrm{C}$ e precipitação média anual de $1.290 \mathrm{~mm}$. Os dados climáticos observados no período experimental (nov./2014 a abr./2015) foram: temperatura média $23,62{ }^{\circ} \mathrm{C}$; umidade relativa média $70,17 \%$; precipitação total $1.057,7 \mathrm{~mm}$; insolação média 7,00 horas dia $^{-1}$ (Embrapa Milho e Sorgo, 2015). Os dados climáticos por decêndio durante o período experimental (temperatura média, precipitação total, insolação média e umidade relativa média) se encontram na Figura 1.

O experimento foi instalado no período primavera/verão dos anos 2014/2015. O delineamento experimental utilizado foi em blocos casualizados, com 3 repetições, e tratamentos dispostos em esquema fatorial $4 \times 4$, sendo 4 doses de nitrogênio $(45,90$, 135 e $\left.180 \mathrm{~kg} \mathrm{ha}^{-1}\right)$ x 4 doses de potássio $(50,100,150$ e $200 \mathrm{~kg} \mathrm{ha}^{-1}$ ) em cobertura, totalizando 48 parcelas para avaliações. 


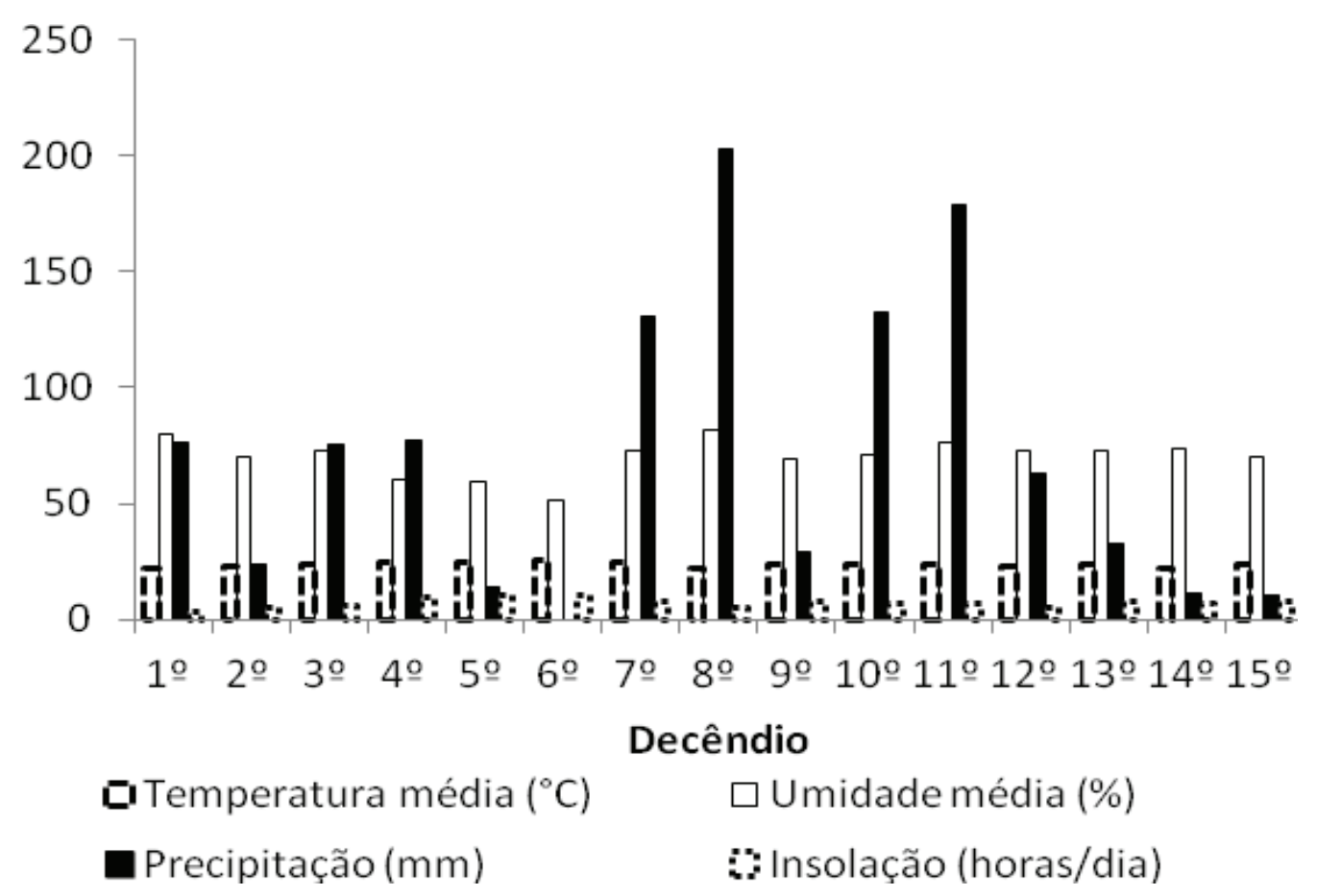

Figura 1. Dados climáticos, por decêndio (24/nov/2014 a 23/abr/2015) durante o período experimental. Temperatura média $\left({ }^{\circ} \mathrm{C}\right)$, precipitação total $(\mathrm{mm})$, insolação total (horas/dia) e umidade relativa média $(\%)$. Fonte: Estação Meteorológica da Embrapa Milho e Sorgo, Sete Lagoas-MG.

No preparo do solo da área experimental foi utilizada grade aradora, grade niveladora e sulcador, um dia antes da semeadura, para marcação das linhas de plantio para semeio manual. A cultivar de sorgo sacarino utilizada foi a BRS 511, recomendada para as condições edafoclimáticas da região Central de Minas Gerais. Esta foi semeada em parcelas com quatro fileiras de cinco metros cada e espaçadas de 0,70 metros. A semeadura foi realizada em 5 de dezembro de 2014 e a emergência ocorreu em 11 de dezembro de 2014, sendo definida em função da época de estabelecimento do início do período chuvoso; isso permitiu colheita ainda na entressafra da cana-de-açúcar.

O desbaste foi feito aos oito dias após a emergência, com o objetivo de manter uma população de 7 plantas $\mathrm{m}^{-1}$ ou 100.000 plantas $\mathrm{ha}^{-1}$. O controle de plantas daninhas foi realizado em pós-emergência do sorgo, aos 8 e 19 dias após a emergência (DAE), com uma capina manual, e aos 22 dias após a emergência, com o uso de Atrazina na dosagem de 4,0 1 ha $^{-1}$. Para o controle dos insetos foi aplicado o inseticida Keshet, na dosagem de $250 \mathrm{ml} \mathrm{ha}^{-1}$, aos 22 dias após a emergência, e aos 33 DAE foi aplicado o inseticida Match, na dosagem de $250 \mathrm{ml} \mathrm{ha}{ }^{-1}$.

A correção do solo com calagem não foi necessária e, em todos os tratamentos, a adubação de semeadura foi de $350 \mathrm{~kg} \mathrm{ha}^{-1}$ da fórmula N-P-K 0828-16, considerando resultados da análise química do solo e uma expectativa de produção acima de $60 \mathrm{tha}^{-1}$ de massa verde (Ribeiro et al., 1999). A adubação de cobertura foi realizada aos 26 dias DAE, quando as plantas apresentavam 5 folhas completamente desen- 
volvidas. O florescimento do sorgo ocorreu entre os 87 e 90 DAE.

A época da colheita aconteceu no período de 110 a 117 DAE. As plantas foram cortadas manualmente e rentes ao solo nas duas linhas centrais, desprezando-se $0,5 \mathrm{~m}$ de bordadura. $\mathrm{O}$ material colhido foi pesado e os valores obtidos, transformados em $\mathrm{kg}$ ha $^{-1}$ para a obtenção da massa verde da planta inteira (colmo, folhas e panícula). Posteriormente retiraram-se seis plantas ao acaso, que foram picadas em uma ensiladeira estacionária e homogeneizadas em uma betoneira acoplada ao equipamento, e deste material foram retiradas e pesadas amostras de cerca de 450 gramas para secagem em estufa com circulação forçada de ar a $65^{\circ} \mathrm{C}$ até peso constante.

Além disso, foram retiradas amostras de $500 \mathrm{~g}$ do material verde triturado (colmos picados e homogeneizados) para extração de caldo e realização das análises dele. $\mathrm{O}$ caldo foi extraído em uma prensa hidráulica Hidraseme, modelo PHS 250, por 60 segundos, com pressão de trabalho de $250 \mathrm{kgf} \mathrm{cm}^{-2}$ sobre essa amostra de 500 gramas. Deste caldo foram coletados os dados de massa de caldo e ${ }^{\circ}$ Brix. Logo após, o caldo foi acondicionado e armazenado em potes de $100 \mathrm{ml}$ e congelado em ultrafreezer a uma temperatura $-55^{\circ} \mathrm{C}$ para conservação até o momento da análise laboratorial. No momento da análise do caldo, ele foi colocado em banho-maria para descongelamento lento e posterior execução dos protocolos de análises laboratoriais.

A seguir, a descrição das metodologias para obtenção das características avaliadas: \% Extração de caldo: após a extração do caldo, ele foi pesado em balança digital e expresso na seguinte fórmula; \% EXT $=($ massa do caldo $/ 500) \times 100$.

Massa verde (MV): pesagem das plantas colhidas na área útil da parcela, em balanças tipo dinamômetro. Os valores obtidos foram expressos em $t \mathrm{ha}^{-1}$.
Massa seca (MS): pré-secagem de amostras de cerca de 450 gramas do material fresco em estufa com ventilação forçada de ar a $65^{\circ} \mathrm{C}$ até peso constante, e pesagem em balança analítica. O peso resultante, com base na massa verde obtida, foi expresso em $\mathrm{t} \mathrm{ha} \mathrm{h}^{-1}$.

Sólidos solúveis totais $\left({ }^{\circ} \mathrm{Brix}\right)$ : mensurado pelo grau ${ }^{\circ}$ Brix com refratômetro digital (Conselho dos Produtores de Cana-de-Açúcar, Açúcar e Álcool do Estado de São Paulo, 2006).

Tonelada de ${ }^{\circ}$ Brix por hectare (TBH): determinado pela fórmula: $\mathrm{TBH}=$ massa verde $\mathrm{x}$ extração $\mathrm{x}$ ${ }^{\circ}$ Brix.

Teor de sacarose (POL): determinado pelo método do Conselho dos Produtores de Cana-de-Açúcar, Açúcar e Álcool do Estado de São Paulo (2006).

Açúcar redutor total (ART): determinado pelo método redutométrico de Somogy, adaptado por Nelson (1944).

Álcool por hectare: determinado pela formula Álcool ha-1=ART x $10 \times 0,6475 \times 0,85 \times$ massa verde $\left(\mathrm{t} \mathrm{ha}^{-1}\right)$ (Institution of Japan Energy, 2006).

Álcool por tonelada de massa verde: determinado pela fórmula $=$ Álcool ha-1 $/$ massa verde $\left(\mathrm{t} \mathrm{ha}^{-1}\right)$.

As análises do caldo foram realizadas no laboratório de Espectrofotometria de Refletância no Infravermelho Proximal (NIRS) na Embrapa Milho e Sorgo, em Sete Lagoas-MG. Não foram consideradas perdas em escala comercial.

Os resultados obtidos foram submetidos à análise de variância, e quando ocorreram diferenças significativas, identificadas pelo teste $\mathrm{F}(\mathrm{P}<0,05)$, foi aplicado o modelo de regressão com o auxílio do programa estatístico SISVAR (Ferreira, 2003). Os modelos para ajuste das equações foram escolhidos com base no coeficiente de determinação e na sua significância. 


\section{Resultados e Discussão}

O resumo das análises de variância, para todas as características estudadas, está apresentado nas Tabelas 1 e 2. Observa-se que houve efeito significativo das doses de nitrogênio sobre massa verde, massa seca, ${ }^{\circ}$ Brix, toneladas de ${ }^{\circ}$ Brix por hectare, teor de sacarose, açúcar redutor total, produção de álcool $\mathrm{t}^{-1}$ de biomassa e produção de álcool ha ${ }^{-1}$. Efeito significativo das doses de potássio ocorreu para ${ }^{\circ}$ Brix, toneladas de ${ }^{\circ}$ Brix por hectare, teor de sacarose, açúcar redutor total e produção de álcool ha-1 .

Não houve diferença significativa nas adubações em cobertura para análise de porcentagem de extração de caldo (Tabela 1). Giacomini et al. (2013) citam que a literatura considera que uma cultivar que apresente $50 \%$ de extração é considerada boa para a produção de etanol. Com isso, pode-se concluir que a cultivar analisada neste trabalho está apta para ser utilizada, considerando que foram obtidas $67,53 \%$ de extração como média e 3.0301 ha $^{-1}$ de rendimento de etanol. Há de se considerar que a prensa hidráulica, com adequada metodologia de uso, pode ter contribuído para a maior eficiência de extração em relação a outros trabalhos citados, em que se fez uso de moendas.

A produtividade de massa verde teve comportamento quadrático em função do aumento da dose de nitrogênio em cobertura (Figura $2 \mathrm{~A}$ ), com máximo valor, estimado pela equação de regressão, obtido com 146,1 $\mathrm{kg} \mathrm{ha}^{-1}$ de nitrogênio. Pereira Filho et al. (2013) em pesquisa com a cultivar sacarina BR 506 e aplicação de $200 \mathrm{~kg} \mathrm{ha}^{-1}$ de nitrogênio obtiveram cerca de $86,0 \mathrm{t} \mathrm{ha}^{-1}$ de massa verde, o que foi bem superior a este trabalho, com 49,39 $\mathrm{t} \mathrm{ha}^{-1}$ na dose de $180 \mathrm{~kg}$ $\mathrm{ha}^{-1}$. Os autores justificam a elevada produtividade do primeiro trabalho como resultado de características genéticas desenvolvidas para a cultura suportar maior número de plantas por área e acumular mais açúcar.

A importância da adubação nitrogenada é ressaltada no trabalho de Teixeira et al. (1999) com a cultivar de sorgo sacarino BR 505, em que na ausência da adubação de cobertura ocorreu uma redução acentuada na massa verde das plantas. Já com a aplicação de $\mathrm{N}$, houve incremento da massa verde, até um ponto máximo (95 $\mathrm{kg} \mathrm{ha}^{-1}$ de $\mathrm{N}$ ) a partir do qual os valores decrescem.

A falta de resposta da produtividade de massa verde em função da adubação potássica pode ser justificada pela alta disponibilidade de potássio no solo, aliada à adubação potássica de plantio. Contudo, Alves et al. (1988) afirmaram que, para uma produtividade média de $60,4 \mathrm{t} \mathrm{ha}^{-1}$ de colmos não desfolhados frescos, as exigências são de $116 \mathrm{~kg} \mathrm{ha}^{-1}$ de $\mathrm{K}_{2} \mathrm{O}$. A variação da precipitação também influencia a concentração de potássio disponível no solo em razão da umidade, pois a umidade do solo melhora a difusão do $\mathrm{K}_{2} \mathrm{O}$, em solução do solo, e promove a sua liberação dos espaços interlaminares da argila de acordo com Mengel e Kirkby (1980). Na Figura 1 (5º decêndio), observa-se que não houve déficit de precipitação e umidade na área experimental na época da adubação em cobertura, mostrando que a difusão e o fluxo de massa, principais mecanismos de transporte de $\mathrm{K}^{+}$da solução do solo até a superfície radicular, não foram afetados.

Com relação à massa verde, este trabalho resultou em 45,73 t ha-1 para a BRS 511, valor este superior às cultivares BRS 506 e BRS 507 avaliadas em diferentes localidades por Albuquerque et al. (2012) considerando o espaçamento de $0,70 \mathrm{~m}$ e a adubação de cobertura com $\mathrm{N}$ e $\mathrm{K}_{2} \mathrm{O}$, ambas de $90 \mathrm{~kg} \mathrm{ha}^{-1}$ (doses contempladas neste trabalho), evidenciando a evolução nessa característica com essa cultivar mais 
Tabela 1. Resumo da análise de variância para porcentagem de extração de caldo (EXT), produtividade de massa verde (MV) e massa seca (MS), em t ha-1 ${ }^{-1}$ de sorgo sacarino BRS 511, em função das doses de $\mathrm{N}$ e de $\mathrm{K}_{2} \mathrm{O}$ em cobertura. UFSJ, Sete Lagoas-MG, 2016.

\begin{tabular}{lllll}
\hline FV & GL & \multicolumn{3}{c}{ Quadrado médio } \\
\hline & & $\%$ EXT & MV & MS \\
\cline { 2 - 4 } $\mathrm{N}$ & 3 & $2,34^{\mathrm{NS}}$ & $406,28^{*}$ & $61,33^{*}$ \\
$\mathrm{~K}$ & 3 & $20,14^{\mathrm{NS}}$ & $118,21^{\mathrm{NS}}$ & $20,81^{\mathrm{NS}}$ \\
$\mathrm{N} * \mathrm{~K}$ & 9 & $28,52^{\mathrm{NS}}$ & $30,04^{\mathrm{NS}}$ & $15,63^{\mathrm{NS}}$ \\
Bloco & 2 & 18,81 & 3332,63 & 234,05 \\
Erro & 30 & 21,36 & 96,79 & 16,97 \\
\hline CV (\%) & & 6,84 & 21,51 & 33,8 \\
Média & 67,53 & 45,73 & 12,18 \\
\hline
\end{tabular}

** significativo a $1 \%$; * significativo a $5 \%$; NS não significativo pelo teste t.

Tabela 2. Resumo da análise de variância para teor de sólidos solúveis totais (SST), toneladas de ${ }^{\circ}$ Brix por hectare (TBH), teor de sacarose (POL), açúcar redutor total (ART), produção de álcool (ALCT), em $1 \mathrm{t}^{-1}$ de biomassa, produção de álcool (ALCH), em 1 ha $^{-1}$, de sorgo sacarino (BRS 511), em função das doses de $\mathrm{N}$ e de $\mathrm{K}_{2} \mathrm{O}$ em cobertura. UFSJ, Sete Lagoas-MG, 2016.

\begin{tabular}{llllllll}
\hline FV & GL & \multicolumn{5}{c}{ Quadrado médio } \\
\cline { 3 - 7 } & & SST & TBH & POL & ART & ALCT & ALCH \\
\cline { 3 - 7 } N & 3 & $37,28^{* *}$ & $11,27^{* *}$ & $26,89^{* *}$ & $26,13^{* *}$ & $790,941^{* *}$ & $5658058^{* *}$ \\
K & 3 & $17,72^{*}$ & $5,01^{* *}$ & $12,84^{*}$ & $7,67^{*}$ & $232,08^{\mathrm{NS}}$ & $1772129^{* *}$ \\
$\mathrm{~N}$ x K & 9 & $6,98^{\mathrm{NS}}$ & $1,08^{\mathrm{NS}}$ & $6,74^{\mathrm{NS}}$ & $8,97^{\mathrm{NS}}$ & $271,83^{\mathrm{NS}}$ & $694411^{\mathrm{NS}}$ \\
Bloco & 2 & 18,79 & 37,22 & 22,13 & 11,64 & 352,57 & 19816096 \\
Erro & 30 & 4,72 & 1,02 & 3,81 & 4,43 & 134,30 & 485443 \\
\hline CV $(\%)$ & & 14,36 & 21,62 & 19,78 & 17,04 & 17,0 & 22,14 \\
Média & & 15,13 & 4,69 & 9,87 & 12,36 & 68,02 & 3146,67 \\
\hline
\end{tabular}

** significativo a $1 \% ;$ * significativo a $5 \%$; NS não significativo pelo teste $\mathrm{t}$.

recentemente disponível no mercado. Entretanto, com os resultados obtidos, pode-se inferir que esse desempenho possivelmente se deve ao maior sucesso da adubação nitrogenada de cobertura que a potássica.

A produtividade de massa seca teve um comportamento linear e crescente em função das doses de $\mathrm{N}$ (Figura 2B), sendo que para o aumento de $1 \mathrm{~kg}$ $\mathrm{ha}^{-1}$ de nitrogênio há um acréscimo de $0,34 \mathrm{~kg} \mathrm{ha}^{-1}$ de massa seca. O valor máximo de massa seca obti- do foi de $14,35 \mathrm{t} \mathrm{ha}^{-1}$, sendo próximo ao encontrado por Oliveira et al. (2005), média de $15,17 \mathrm{t} \mathrm{ha}^{-1}$, que trabalhando com diferentes genótipos de sorgo (BRS 610, CMSXS 762, BR 506 e BR700) não obtiveram resposta dessa variável às doses de nitrogênio. Esses autores observaram ainda que a extração de nutrientes pela planta seguiu a seguinte ordem: $\mathrm{K}>\mathrm{N}>\mathrm{Ca}>$ $\mathrm{Mg}>\mathrm{P}>\mathrm{S}>\mathrm{Fe}>\mathrm{B}>\mathrm{Mn}>\mathrm{Zn}>\mathrm{Cu}$, o que evidencia a importância deste trabalho com doses de nitrogênio e potássio. 
A produtividade máxima de massa seca foi obtida na maior dose de $\mathrm{N}$ avaliada, porém essa produtividade foi inferior à produtividade de cultivares de sorgo forrageiro disponíveis no mercado, como para a cultivar BRS 655, que apresentou produtividade de massa seca entre 15 e 18 t ha-1 $^{-1}$ (Rodrigues et al., 2008).

A resposta dos sólidos solúveis totais às doses de $\mathrm{N}$ de cobertura foi quadrática (Figura $3 \mathrm{~A}$ ), com máximo valor, estimado pela equação de regressão obtido com 120,02 $\mathrm{kg} \mathrm{ha}^{-1}$ de nitrogênio. O valor médio encontrado neste trabalho foi de $15,13{ }^{\circ}$ Brix, sendo pouco inferior aos obtidos por Pereira Filho et al. (2013), que trabalhando com materiais de sorgo sacarino (diferentes híbridos e densidades) encontraram valor médio de $15,62{ }^{\circ}$ Brix, com aplicação de $200 \mathrm{~kg} \mathrm{ha}^{-1}$ de nitrogênio. Já Santos et al. (2015), em pesquisa com diferentes doses de $\mathrm{N} \mathrm{e}_{2} \mathrm{O}$, observaram que a dose de $80 \mathrm{~kg} \mathrm{ha}^{-1}$ para ambos os nutrientes proporcionou o maior valor de ${ }^{\circ}$ Brix, e Parrella et al. (2010), avaliando 25 genótipos de sorgo sacarino, em cinco locais, alcançaram ${ }^{\circ}$ Brix médio de 18,42.
De acordo com May et al. (2013), a produção de etanol se torna viável economicamente quando o sorgo sacarino apresenta um ART mínimo de $12,5 \%$, que corresponde a um valor de 14,25 a $14,50{ }^{\circ}$ Brix, sendo diretamente influenciado pela atividade fotossintética. Esta, por sua vez, depende da interceptação da radiação fotossinteticamente ativa, ou seja, o arranjo de plantas pode influenciar diretamente o valor do ${ }^{\circ}$ Brix. O autor ainda relata que os níveis de fertilidade do solo, temperatura, disponibilidade hídrica e radiação disponível também afetam diretamente essa característica. Então, neste trabalho, o valor encontrado foi dentro da faixa esperada para uma boa produção de etanol.

Considerando o potássio, a resposta às doses aplicadas em cobertura também apresentou comportamento quadrático (Figura $3 \mathrm{~B}$ ), com máximo valor, estimado pela equação de regressão, obtido com $128,76 \mathrm{~kg} \mathrm{ha}^{-1}$ de $\mathrm{K}_{2} \mathrm{O}$. Rosolem et al. (1982), aplicando diferentes doses de nitrogênio e potássio em duas cultivares e em dois tipos de solo, confirmaram a importância da adubação em cobertura com potássio,

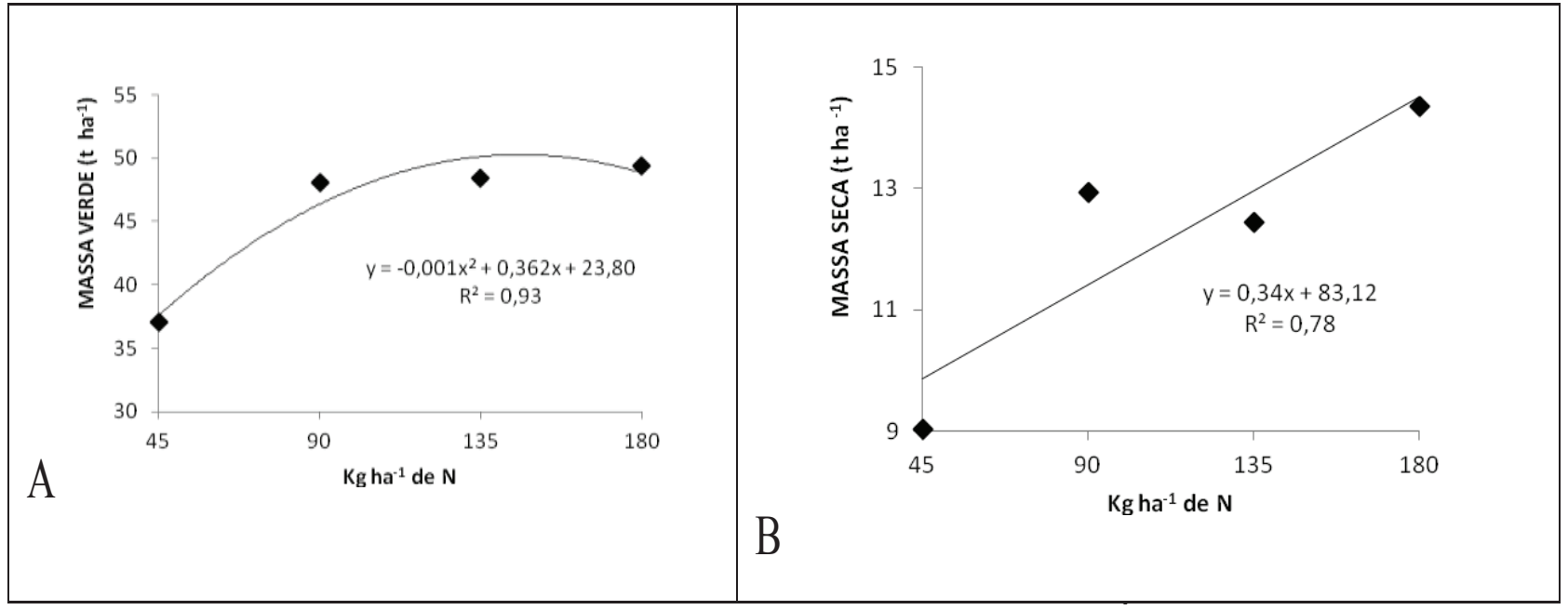

Figura 2. A- Produtividade de massa verde de sorgo sacarino $\left(\mathrm{t} \mathrm{ha} \mathrm{H}^{-1}\right)$ em função das doses de $\mathrm{N}$, considerando quatro doses de $\mathrm{K}_{2} \mathrm{O}\left(50,100,150\right.$ e $\left.200 \mathrm{~kg} \mathrm{ha}^{-1}\right)$. B-Produtividade de massa seca de sorgo sacarino ( $\left.\mathrm{t} \mathrm{ha}^{-1}\right) \mathrm{em}$ função das doses de $\mathrm{N}$ em cobertura, considerando quatro doses de $\mathrm{K}_{2} \mathrm{O}\left(50,100,150\right.$ e $\left.200 \mathrm{~kg} \mathrm{ha}^{-1}\right)$. UFSJ, Sete Lagoas, MG-2016. 
pois mesmo nos tratamentos sem adubação nitrogenada houve ganhos no teor de sólidos solúveis com a aplicação do potássio, mesmo com alta disponibilidade no solo.

Nos trabalhos supracitados, observa-se que a produtividade de massa verde reflete positivamente na produção de caldo. Entretanto, o conteúdo de açúcares no caldo e, por consequência, a conversão em etanol é dependente de cultivar, fatores ambientais, época de colheita, eficiência de processos de transporte e de conversão industrial. Assim, os valores encontrados neste trabalho para os sólidos solúveis totais ficaram na faixa de limite mínimo considerado pela indústria (15 a $19^{\circ}$ Brix) (Pacheco, 2012).

A quantidade de toneladas de ${ }^{\circ}$ Brix por hectare $(\mathrm{TBH})$ apresentou comportamento quadrático em função do aumento das doses de nitrogênio e potássio em cobertura, com o máximo valor estimado pela equação de regressão com $133,5 \mathrm{~kg} \mathrm{ha}^{-1}$ tanto de $\mathrm{N}$ quanto de $\mathrm{K}_{2} \mathrm{O}$ (Figuras $3 \mathrm{C}$ e D).

A quantidade de toneladas de ${ }^{\circ}$ Brix por hectare abrange os caracteres de massa verde, porcentagem de extração de caldo e sólidos solúveis totais, influenciando a produção de etanol por hectare e sendo adequada para selecionar genótipos superiores de sorgo sacarino.

Neste trabalho, obteve-se média de 4,69 para TBH. Contudo, a diferença de valores de TBH deste trabalho em comparação com outros trabalhos é, em parte, explicada pelo fato de que mesmo com menor produtividade de massa verde obtida neste trabalho, foram alcançados maiores valores de TBH em função de a cultivar BRS 511 ter apresentado valores mais altos de ${ }^{\circ}$ Brix e de porcentagem de extração de caldo, nas condições avaliadas.

A cultura da cana-de-açúcar apresenta valores de $\mathrm{TBH}$ maiores se comparados aos do sorgo sacarino, porém, essa superioridade se justifica pela maior quantidade de biomassa produzida por hectare. Assim, se dois dos caracteres estiverem com valores altos, o TBH terá valor satisfatório, tornando-se, desta forma, uma característica importante para a seleção de genótipos para alta produção de etanol.

O teor de sacarose apresentou comportamento quadrático em função do aumento das doses de nitrogênio e de potássio em cobertura, com valores máximos, estimados pela equação de regressão, obtidos com 120,18 e 128,27 $\mathrm{kg} \mathrm{ha}^{-1}$ de $\mathrm{N}$ e $\mathrm{K}_{2} \mathrm{O}$, respectivamente. Entretanto, observou-se valor médio de teor de sacarose de $9,87 \%$ para ambas as adubações (Figuras 4 A e B). Assim, este trabalho corrobora o de Pacheco (2012), que afirmam que o caldo de sorgo sacarino possui uma composição diferente em relação ao da cana-de-açúcar, possuindo mais glicose e menos sacarose e amido.

Rosolem et al. (1982), em trabalho com duas cultivares de sorgo sacarino (Brandes e Rio) em dois solos e aplicação de $\mathrm{N}, \mathrm{P}_{2} \mathrm{O}_{5}$ e $\mathrm{K}_{2} \mathrm{O}$, observaram que no Latossolo Roxo, com a aplicação de N, o teor de sacarose teve aumento moderado na cultivar Brandes, e este foi mais evidente do que na cultivar Rio, alcançando como média de $11,9 \%$. Considerando o potássio, não houve resposta significativa. Já Uriber e Ticianeli (2014), em trabalho com sorgo sacarino na região de São Paulo em diferentes densidades e com adubação de plantio de $30,50,50$ e $40 \mathrm{~kg} \mathrm{ha}^{-1}$ de $\mathrm{N}, \mathrm{P}_{2} \mathrm{O}_{5}, \mathrm{~K}_{2} \mathrm{O}$ e $\mathrm{S}$, respectivamente, obtiveram maior teor de sacarose $(15,10 \%)$ com maior densidade de plantas (142.857 plantas ha-1). Esses valores encontrados para o teor de sacarose pelos autores são maiores do que as deste trabalho (média de 9,87\%). De acordo com Sandeep et al. (2010), o caldo acumula o máximo de açúcares quando os grãos 


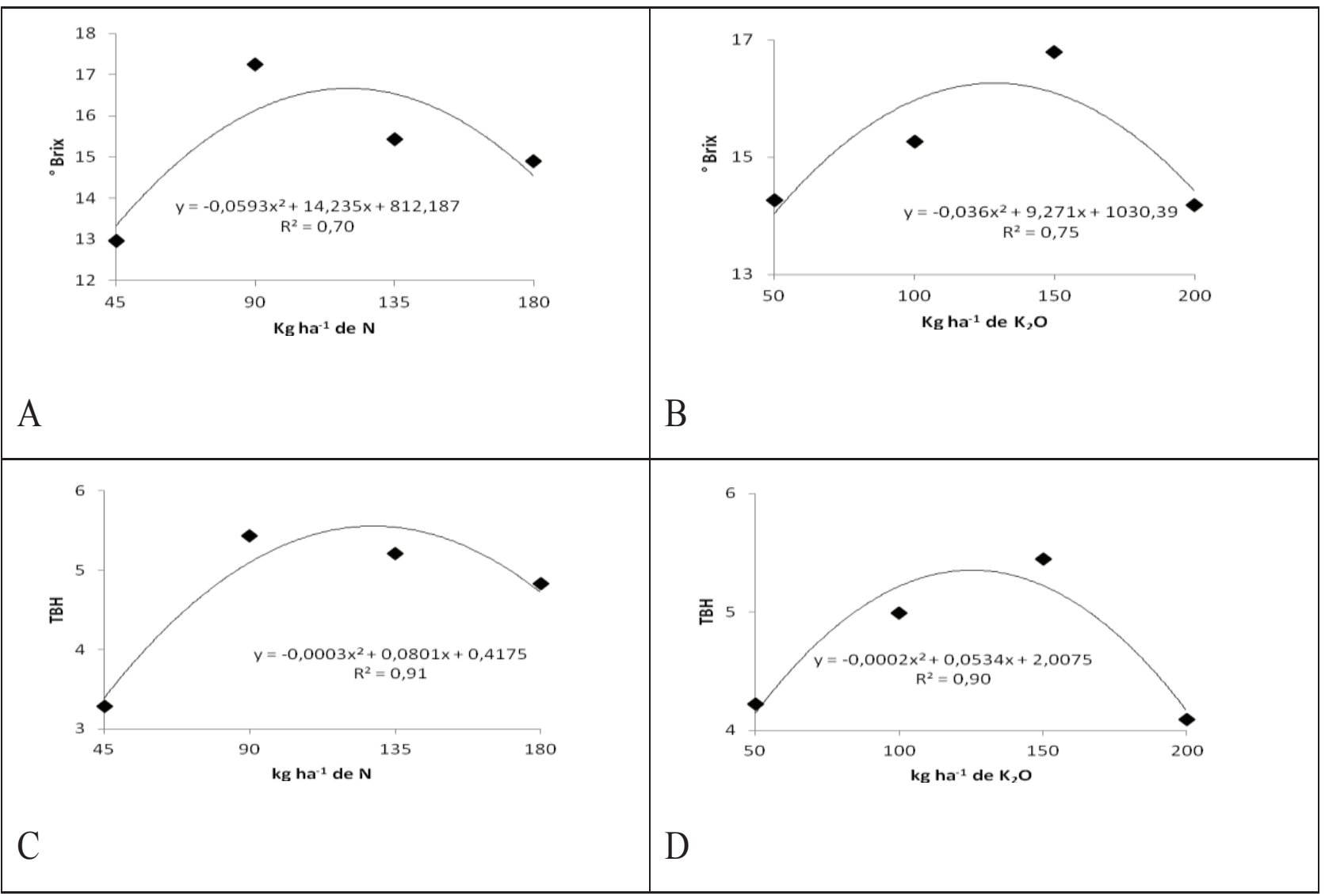

Figura 3. A- Sólidos solúveis totais de sorgo sacarino ( ${ }^{\circ}$ Brix) em função das doses de N, considerando quatro doses de $\mathrm{K}_{2} \mathrm{O}\left(50,100,150\right.$ e $\left.200 \mathrm{~kg} \mathrm{ha}^{-1}\right)$, B- e em função das doses de $\mathrm{K}_{2} \mathrm{O}$ considerando quatro doses de $\mathrm{N}\left(45,90,135\right.$ e $\left.180 \mathrm{~kg} \mathrm{ha}^{-1}\right)$, C- Toneladas de ${ }^{\circ}$ Brix por hectare de sorgo sacarino (TBH) em função das doses de $\mathrm{N}$, considerando quatro doses de $\mathrm{K}_{2} \mathrm{O}\left(50,100,150\right.$ e $\left.200 \mathrm{~kg} \mathrm{ha}^{-1}\right)$, D- e em função das doses de $\mathrm{K}_{2} \mathrm{O}$ considerando quatro doses de N (45, 90, 135 e $\left.180 \mathrm{~kg} \mathrm{ha}^{-1}\right)$. UFSJ, Sete Lagoas-MG, 2016.

atingem a maturidade fisiológica, porém, de acordo com Wang et al. (2009), os valores estão adequados dentro do limite. Assim, os autores acrescentam que na maturidade fisiológica o caldo contém entre 10 e $25 \%$ de açúcares (principalmente sacarose, glicose e frutose).

Anteriormente, a qualidade da matéria-prima para produção de etanol era determinada somente pelo teor de sacarose, mas atualmente se analisam as características físico-químicas e microbiológicas que afetam a recuperação do açúcar na fábrica e a qua- lidade do produto final. Dentre essas características estão os fatores intrínsecos (sacarose, açúcar redutor, fibras, temperatura, chuva, etc.) e extrínsecos (restos de culturas e plantas invasoras) (Vian, 2009).

Assim, analisando o açúcar redutor total, este apresentou comportamento quadrático em função do aumento das doses de nitrogênio e de potássio em cobertura, com valores máximos, estimados pela equação de regressão, obtidos com 123,4 e $130,27 \mathrm{~kg} \mathrm{ha}^{-1}$ de $\mathrm{Ne} \mathrm{K}_{2} \mathrm{O}$, respectivamente (Figuras $4 \mathrm{C}$ e D). Este comportamento mostrado 
neste trabalho permite inferir que para açúcar redutor total há um ponto máximo a partir do qual não há mais resposta aos acréscimos de $\mathrm{N}$ e $\mathrm{K}_{2} \mathrm{O}$ em cobertura.

Como o ART representa a somatória dos açúcares redutores e da sacarose invertida por hidrólise ácida ou enzimática pela invertase, a porcentagem mínima de $12 \%$ deve ser levada em consideração para que a levedura, no processo de industrialização, converta completamente este nível de açúcar em etanol dentro do tempo adequado.
Segundo May et al. (2013), a viabilização econômica da produção de etanol a partir do sorgo sacarino requer níveis mínimos de teor de açúcar total no caldo, que se situa em torno de $12,5 \%$, correspondente a ${ }^{\circ}$ Brix de 14,25 a 14,50. Estes valores de referência se assemelham aos resultados obtidos nesse trabalho. Assim, é viável se fazer uma adubação nitrogenada e potássica em cobertura em sorgo sacarino para ganhos em ${ }^{\circ}$ Brix, notadamente com valores até cerca de 120 e $130 \mathrm{~kg} \mathrm{ha}^{-1}$ de $\mathrm{N}$ e de $\mathrm{K}_{2} \mathrm{O}$, respectivamente.

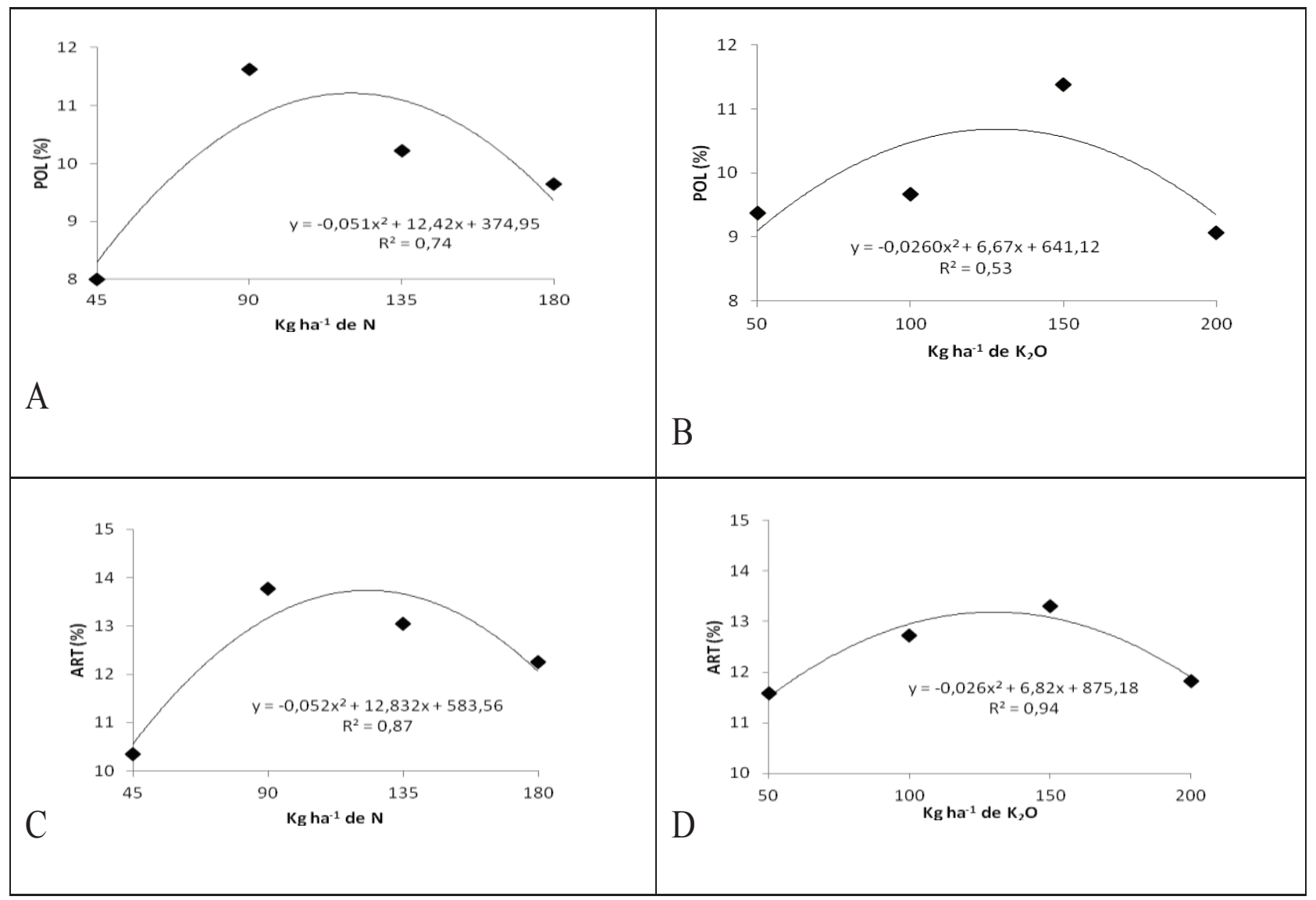

Figura 4. A- Teor de sacarose de sorgo sacarino (POL \%) em função das doses de N, considerando quatro doses de $\mathrm{K}_{2} \mathrm{O}\left(50,100,150\right.$ e $\left.200 \mathrm{~kg} \mathrm{ha}^{-1}\right)$, B- e em função das doses de $\mathrm{K}_{2} \mathrm{O}$ considerando quatro doses de $\mathrm{N}$ $\left(45,90,135\right.$ e $\left.180 \mathrm{~kg} \mathrm{ha}^{-1}\right)$. C- Açúcar redutor total (\%) em função das doses de N, considerando quatro doses de $\mathrm{K}_{2} \mathrm{O}\left(50,100,150\right.$ e $\left.200 \mathrm{~kg} \mathrm{ha}^{-1}\right)$, D - e em função das doses de $\mathrm{K}_{2} \mathrm{O}$ considerando quatro doses de $\mathrm{N}$ (45, 90, 135 e $180 \mathrm{~kg} \mathrm{ha}^{-1}$ ). UFSJ, Sete Lagoas-MG, 2016. 
A produção média de álcool por tonelada de massa verde teve comportamento quadrático em função do aumento das doses de nitrogênio e de potássio em cobertura, com valores máximos, estimados pela equação de regressão de 56,98 e $75,831 \mathrm{t} \mathrm{t}^{-1}$, com as doses de 123,45 e $130,42 \mathrm{~kg}$ $\mathrm{ha}^{-1}$ de $\mathrm{N}$ e $\mathrm{K}_{2} \mathrm{O}$, respectivamente (Figuras $5 \mathrm{~A}$ e B). O valor médio da produção de álcool foi de $68,031 \mathrm{t}^{-1}$ de massa verde.

Como existe uma relação direta entre litros de etanol produzidos por hectare e litros de etanol produzido por tonelada de biomassa, Emygdio et al. (2011) estimaram, para a cultivar de sorgo sacarino BR 506, uma média de 55 litros de etanol por tonelada de colmos verde, e, considerando uma média de produtividade entre 48 e 70 t ha $^{-1}$ de colmos verdes, seria possível produzir entre 2.640 1 ha $^{-1}$ e 3.8501 ha $^{-1}$ de etanol.

Entretanto, valor médio de litros de etanol produzido por tonelada de massa verde encontrado neste trabalho está abaixo do valor obtido por May et al. (2012), então, esse se torna mais um motivo para sugerir a adoção de outras práticas de manejo e condições climáticas para o bom desempenho agroindustrial de cultivares de sorgo sacarino.

A produção de álcool por hectare teve comportamento quadrático em função do aumento das doses de nitrogênio e de potássio em cobertura com valores máximos, estimados pela equação de regressão, com 132,15 e 127,04 $\mathrm{kg} \mathrm{ha}^{-1}$ de $\mathrm{N}$ e $\mathrm{K}_{2} \mathrm{O}$, respectivamente (Figura $5 \mathrm{C}$ e D). Nos diferentes tratamentos, os valores obtidos neste trabalho variaram entre 2.129 e 3.606 litros ha-1 de etanol, com média de 3.146, 771 ha $^{-1}$ de etanol.

Com a aplicação de $\mathrm{N}$, a produção de litros por hectare de etanol responde significati- vamente à aplicação de $\mathrm{N}$, alcançando como média 3.9361 ha $^{-1}$ (Rosolem et al., 1982). Já Zhao et al. (2009) avaliaram cinco cultivares de sorgo sacarino em Pequim, na China, com três épocas de corte após o florescimento, e obtiveram rendimentos de 1.2811 ha $^{-1}$ a 5.4141 ha $^{-1}$ de etanol. No Brasil, Araújo (2012) comentam que a produção encontrada de etanol não passa de $3.5001 \mathrm{ha}^{-1}$ por causa da falta de manejo e planejamento da lavoura. Entretanto, Emygdio et al. (2011) encontraram maiores valores ao estimar para o sorgo sacarino BR 506 uma produção entre 2.6401 ha $^{-1}$ e 3.8501 ha $^{-1}$ de etanol através de uma média de colmos entre 48 e $70 \mathrm{t} \mathrm{ha}^{-1}$.

As diferentes produtividades de etanol encontradas pelos autores ainda são inferiores às de experimentos realizados pela Embrapa, onde as variedades analisadas são superiores na produção de etanol em comparação aos híbridos presentes no mercado, apresentando 751 $\mathrm{t}^{-1}$ de biomassa e produção de álcool superior a $4.3251 \mathrm{ha}^{-1}$ (May et al., 2012). Contudo, como a produção de etanol considera o teor de ART e massa verde em sua composição, o valor deste trabalho pode ter sido inferior. Esses resultados justificam a prática da adubação de nitrogênio e potássio em cobertura para o bom desempenho industrial desta cultivar.

Observa-se uma resposta significativa da maioria das características agroindustriais analisadas para o aumento das doses de nitrogênio em cobertura, o que não ocorreu para todas as características quanto ao acréscimo das doses de potássio. Entretanto, evidencia-se que é necessária uma boa dose de potássio em cobertura, cerca de $130 \mathrm{~kg} \mathrm{ha}^{-1}$, mesmo o solo apresentando um teor alto desse nutriente. 


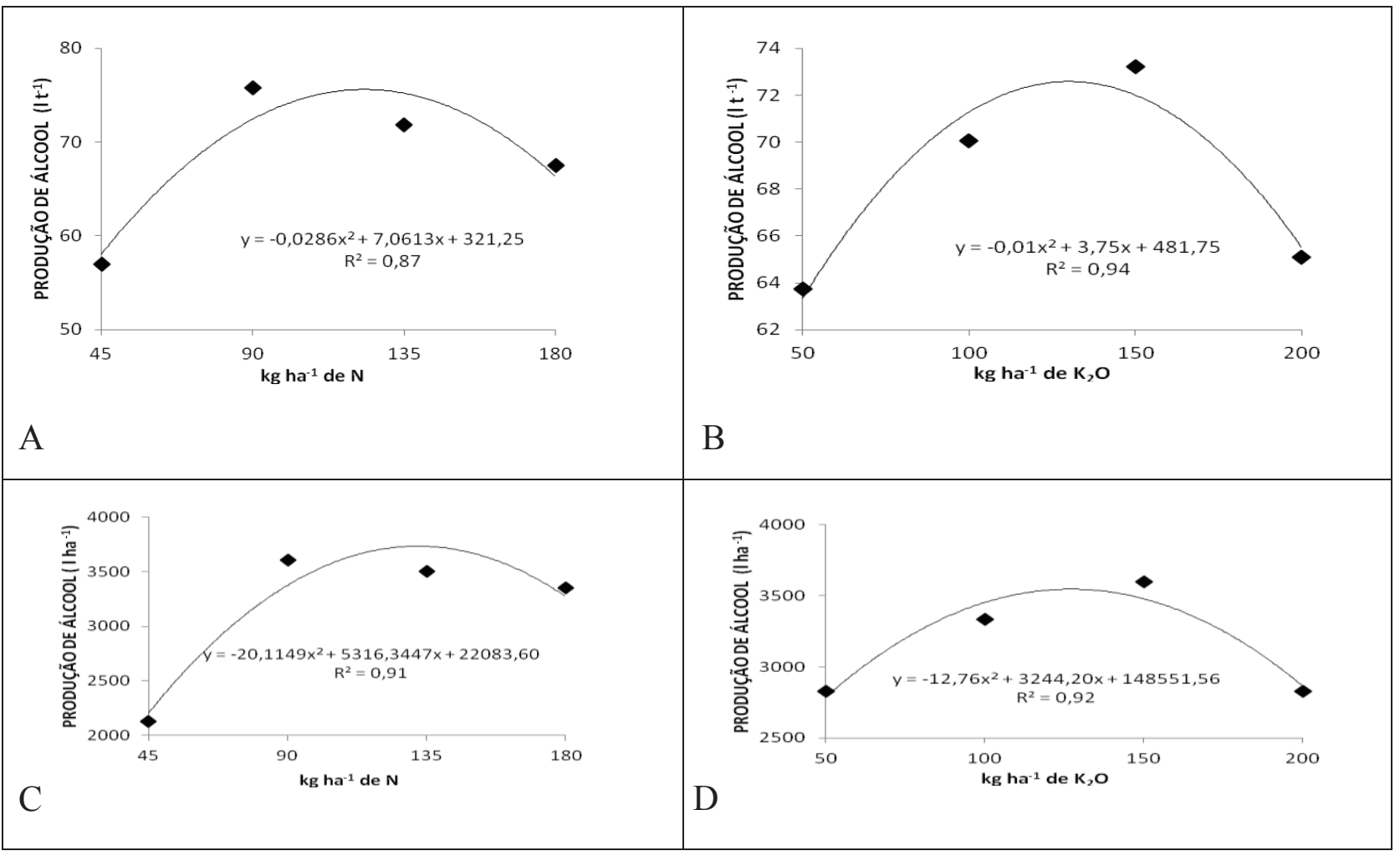

Figura 5. A- Produção de álcool de sorgo sacarino ( $\left(\mathrm{t}^{-1} \mathrm{de}\right.$ massa verde de colmos) em função das doses de $\mathrm{N}$, considerando quatro doses de $\mathrm{K}_{2} \mathrm{O}\left(50,100,150\right.$ e $\left.200 \mathrm{~kg} \mathrm{ha}^{-1}\right)$, B; e em função das doses de $\mathrm{K}_{2} \mathrm{O}$; considerando quatro doses de $\mathrm{N}\left(45,90,135\right.$ e $\left.180 \mathrm{~kg} \mathrm{ha}^{-1}\right)$. C -Produção de álcool de sorgo sacarino (1 ha $\left.{ }^{-1}\right)$ em função das doses de $\mathrm{N}$, considerando quatro doses de $\mathrm{K}_{2} \mathrm{O}\left(50,100,150\right.$ e $\left.200 \mathrm{~kg} \mathrm{ha}^{-1}\right)$. D- e em função das doses de $\mathrm{K}_{2} \mathrm{O}$ considerando quatro doses de N (45, 90, 135 e $\left.180 \mathrm{~kg} \mathrm{ha}^{-1}\right)$. UFSJ, Sete Lagoas-MG, 2016.

\section{Conclusões}

O sorgo sacarino responde à adubação nitrogenada e potássica em cobertura, sendo que adubação nitrogenada interfere mais nas diversas variáveis analisadas em relação ao potássio.

O melhor desempenho do sorgo sacarino, considerando a produção de litros de etanol por hectare, toneladas de ${ }^{\circ}$ Brix por hectare, litros de etanol por tonelada de massa verde, teor de sacarose e açúcar redutor total foi obtido com o uso de doses altas de $\mathrm{N}$ e $\mathrm{K}_{2} \mathrm{O}$ em cobertura (cerca de 120 e $130 \mathrm{~kg} \mathrm{ha}^{-1}$, respectivamente).

\section{Agradecimentos}

Ao professor e orientador Iran Dias Borges, pela confiança, disponibilidade e apoio; à UFSJ, pela oportunidade de realizar o curso de Pós-graduação; à Embrapa Milho e Sorgo, de Sete Lagoas, em especial aos pesquisadores Flávia Cristina dos Santos e Rafael Augusto da Costa Parrella, pelo apoio e incentivo à pesquisa.

\section{Referências}

ALBUQUERQUE, C. J. B.; TARDIN, F. D.; PARRELLA, R. A. C.; GUIMARÂES, A. S.; OlIVEIRA, R. M.; 
SILVA, K. M. J. Sorgo sacarino em diferentes arranjos de plantas e localidade de Minas Gerais, Brasil. Revista Brasileira de Milho e Sorgo, Sete Lagoas, v. 11, n. 1, p. 69-85, 2012.

DOI: $10.18512 / 1980-6477 /$ rbms.v11n1p69-85.

ALVES, A. C.; BRAUNER, J. L.; CORDEIRO, D. S.; ZONTA, E. P.; CORREA, L. A. V. Exigências nutricionais em potássio, cálcio e magnésio do sorgo sacarino. Pesquisa Agropecuária Brasileira, Brasília, v. 23, n. 5, p. 529536,1988 .

ARAÚJO, C. Evolução do sorgo sacarino para produção de etanol é viável. Brasília, DF: Embrapa, 2012. Notícias. Disponível em: <http://www.embrapa.br/busca-denoticias/-/noticia/1484977/evolucao-do-sorgo-sacarinopara-producao-de-etanol-e-viavel>. Acesso em: 8 fev. 2016.

BORÉM A.; PIMENTEL L.; PARRELLA R. Sorgo: do plantio à colheita. Viçosa, MG: Universidade Federal de Viçosa, 2014. 275 p.

CONSELHO DOS PRODUTORES DE CANA-DEAÇÚCAR, AÇÚCAR E ÁLCOOL DO ESTADO DE SÃO PAULO - CONSECANA. Manual de instruções. 5. ed. Piracicaba, 2006. 112 p.

DURÃES, F. O. M. Sorgo sacarino: tecnologia agronômica e industrial para alimentos e energia. Agroenergia em Revista, Brasília, n. 3, p. 14-52, 2011.

EMBRAPA MILHO E SORGO. Dados climáticos. Sete Lagoas, 2015. Disponível em: <http://www.cnpms. embrapa.br>. Acesso em: 25 maio 2015.

EMYGDIO, B. M.; AFONSO, A. P. S.; OLIVEIRA, A. C. B.; PARRELLA, R. SCHAFFERT, R. E.; MAY, A. Desempenho de cultivares de sorgo sacarino para a produção de etanol sob diferentes densidades de plantas. Pelotas: Embrapa Clima Temperado, 2011. 22 p. (Embrapa Clima Temperado. Boletim de Pesquisa e Desenvolvimento, 156).

FERREIRA, D. F. SISVAR para Windows 4.3. Lavras: UFLA, 2003. Software.
GIACOMINI, I.; SIQUEIRA, F. L. T.; PEDROZA, M. M.; MELLO, S. Q. S.; CERQUEIRA, F. B.; SALLA, L. Uso potencial de sorgo sacarino para a produção de etanol no Estado do Tocantins. Revista Agrogeoambiental, Pouso Alegre, v. 5, n. 3, p. 73-81, 2013.

INSTITUTION OF JAPAN ENERGY. World energy outlook. Paris: Biomass International Energy Agency, 2006. Disponível em: <http://www.iea.org $>$. Acesso em: 2 dez. 2014.

MAGALHÃES, P. C.; DURÃES, F. O. M. Ecofisiologia da produção de sorgo. Sete Lagoas: Embrapa Milho e Sorgo, 2003. 4 p. (Embrapa Milho e Sorgo. Comunicado Técnico, 87).

MAY, A.; MENDES, S. M.; SILVA, D. D. da; PARRELLA, R. A. da C.; MIRANDA, R. A. de; SILVA, A. F. da; PACHECO, T. F.; AQUINO, L. A. de; COTA, L. V.; COSTA, R. V. da; KARAM, D.; PARRELLA, N. N. L. D.; SCHAFFERT, R. E. Cultivo de sorgo sacarino em áreas de reforma de canaviais. Sete Lagoas, MG: Embrapa Milho e Sorgo, 2013. 36 p. (Embrapa Milho e Sorgo. Circular Técnica, 186). Disponível em <http:// www.infoteca.cnptia.embrapa.br/bitstream/doc/966886/1/ circ186.pdf>. Acesso em: 12 dez. 2014.

MAY, A.; DURÃES, F. O. M.; PEREIRA FILHO, I. A.; SCHAFFERT, R. E.; PARRELlA, R. A. da C. (Ed.). Sistema Embrapa de produção agroindustrial de sorgo sacarino para bioetanol: Sistema BRS1G-Tecnologia Qualidade Embrapa. Sete Lagoas: Embrapa Milho e Sorgo, 2012. (Embrapa Milho e Sorgo. Documentos, 139).

MENGEL, K.; KIRKBY, E. A. Potassium in crop production. Advances in Agronomy, New York, v. 33, p. 59-110, 1980. DOI: 10.1016/S0065-2113(08)60164-9.

NELSON, N. A fotometric adaptation of Somogy method for the determination of glucose. Jornal of Biologic Chemistry. Cincinnati, v. 153, p. 375-380, 1944.

OLIVEIRA, R. P.; FRANÇA, A. F. S.; RODRIGUES FILHO, O.; OLIVEIRA, E. R.; ROSA, B.; SOARES, T. V.; MELLO, S. Q. S. Características agronômicas de cultivares 
de sorgo (Sorghum bicolor (L.) Moench) sob três doses de nitrogênio. Pesquisa Agropecuária Tropical, Goiânia, v. 35 , n. 1, p. 45-53, 2005.

OMETTO, J. C. Classificação climática. In: OMETTO, J. C. Bioclimatologia tropical. São Paulo: Ceres, 1981. p. 390-398.

ORTEGA, E.; WATANABE, M.; CAVALETT, O. A produção de etanol em micro e minidestilarias. Disponível em: <http://www.unicamp.br/fea/ortega/ MarcelloMello/mini-usina-Ortega.pdf $>$. Acesso em: 13 jun. 2016.

PACHECO, T. F. Tecnologia industrial. In: MAY, A.; DURÃES, F. O. M.; PEREIRA FILHO, I. A.; SCHAFFERT, R. E.; PARRELLA, R. A. da C. (Ed.). Sistema Embrapa de produção agroindustrial de sorgo sacarino para bioetanol: Sistema BRS1GTecnologia Qualidade Embrapa. Sete Lagoas: Embrapa Milho e Sorgo, 2012. p. 92-106. (Embrapa Milho e Sorgo. Documentos, 139).

PARENTE, H. N.; SILVA JÚNIOR, O. R. S.; BANDEIRA, J. R.; PARENTE, M. O. M.; RODRIGUES, R. C.; ROCHA, K. S.; GOMES, R. M. S. Produtividade do sorgo forrageiro em função de quantidades crescentes de adubação fosfatada e nitrogenada. Revista Trópica: Ciências Agrárias e Biológicas, Chapadinha, v. 8, n. 1, p. 1-10, 2014.

PARRELLA, R. A. C.; RODRIGUES, J. A. S.; TARDIN, F. D.; DAMASCENO, C. M. B.; SCHAFFERT, R. E. Desenvolvimento de híbridos de sorgo sensíveis ao fotoperíodo visando alta produtividade de biomassa. Sete Lagoas: Embrapa Milho e Sorgo, 2010. 25 p. (Embrapa Milho e Sorgo. Boletim de Pesquisa e Desenvolvimento, 28).

PLANO Nacional de Agroenergia 2006-2011. Brasília, DF: Ministério da Agricultura, Pecuária e Abastecimento: Embrapa, Secretaria de Gestão Estratégica, 2005. 118 p. Disponível em: <http://www.agricultura.gov.br/arq editor/ file/Ministerio/planos\%20e \%20programas/PLANO $\% 20$ NACIONAL\%20DE\%20AGROENERGIA. pdf $>$. Acesso em: 2 dez. 2014.
PEREIRAFILHO, I.A.; PARRELLA, R.A. C.; MOREIRA, J. A. A.; MAY, A.; SOUZA, V. F.; CRUZ, J. C. Avaliação de cultivares de sorgo sacarino [Sorghum bicolor (L.) Moench] em diferentes densidades de semeadura visando a características importantes na produção de etanol. Revista Brasileira de Milho e Sorgo, Sete Lagoas, v. 12, n. 2, p. 118-127, 2013.

DOI: 10.18512/1980-6477/rbms.v12n2p118-127.

RESENDE A. V.; COELHO, A. M.; RODRIGUES, J. A. S.; SANTOS, F. C. Adubação maximiza o potencial produtivo do sorgo. Sete Lagoas: Embrapa Milho e Sorgo, 2009, 8 p. (Embrapa Milho e Sorgo. Circular Técnica, 119).

RIBEIRO, A. C.; GUIMARÃES, P. T. G.; ALVAREZ V., V. H. (Ed.). Recomendações para o uso de corretivos e fertilizantes em Minas Gerais: $5^{\text {a }}$ aproximação. Viçosa, MG: Comissão de Fertilidade do Solo do Estado de Minas Gerais, 1999. 359 p.

RODRIGUES, J. A. S.; SANTOS, F. G.; SHAFFERT, R. E.; FERREIRA, A. S.; CASELA, C. R.; TARDIN, F. D. BRS 655: híbrido de sorgo forrageiro para produção de silagem de alta qualidade. Sete Lagoas: Embrapa Milho e Sorgo, 2008. 2 p. (Embrapa Milho e Sorgo. Circular Técnica, 107).

ROSOLEM, C. A.; MALAVOLTA, E.; BRINHOLI, O.; SERRA, G. E. Respostas do sorgo sacarino a N, P e K II. Características tecnológicas. Pesquisa Agropecuária Brasileira, Brasília, v. 17, n. 3, p. 385-391, 1982.

SANDEEP, R. G.; GURURAJA RAO, M. R.; RAMESH, S.; CHIKKALINGAIAH; SHIVANNA, H. Parental combining ability as a good predictor of productive crosses in sweet sorghum [Sorghum bicolor (L.) Moench]. Journal of Applied and Natural Science, v. 2, n. 2, p. 245-250, 2010.

SANTOS, F. C.; COELHO, A. M.; RESENDE, A. V.; MIRANDA, R. A. Correção do solo e adubação na cultura do sorgo. Informe Agropecuário, Belo Horizonte, v. 35, n. 278, p. 76-88, 2014. 
SANTOS, F. C.; RESENDE, A. V.; ALBUQUERQUE FILHO, M. R.; MAY, A.; CRUZ, S. C. B.; GRAVINA, G. A.; PARRELLA, R. A.C. Resposta do sorgo sacarino à adubação NPK em latossolo de cerrado da região Central de Minas Gerais. Sete Lagoas: Embrapa Milho e Sorgo, 2015. 35 p. (Embrapa Milho e Sorgo. Boletim de Pesquisa e desenvolvimento, 130). Disponível em: $<$ http:// www.infoteca.cnptia.embrapa.br/handle/doc/1037738>. Acesso em: 5 fev. 2016.

TEIXEIRA, C. G.; JARDINE, J. G.; NICOLELLA, G.; ZARONI, M. H. Influência da época de corte sobre o teor de açucares de colmos de sorgo sacarino. Pesquisa Agropecuária Brasileira, Brasília, v. 34, n. 9, p. 16011606, 1999. DOI: 10.1590/S0100-204X1999000900010.

URIBER, R. A. M.; TICIANELI, L. C. S. Influência do estande na produtividade de sorgo sacarino. Revista Diálogos \& Ciência, Salvador, v. 34, p. 10-12, 2014.

VIAN, C. E. F. Qualidade de matéria seca. In: MARIN, R. (Ed.). Cana-de-açúcar. Brasília, DF, 2009. Disponível em: <http://www.agencia.cnptia.embrapa.br/gestor/canade-acucar/arvore/CONTAG01_138_22122006154842. html>. Acesso em: 17 jan. 2016.

VON PINHO, R. G.; VASCONCELOS, R. C. Cultura do sorgo. Lavras: UFLA, 2002. 76 p.

ZHAO, Y. L.; DOLAT, A.; STEINBERGER, Y.; WANG, X.; OSMAN, A.; XIE, G. H. Biomass yield and changes in chemical composition of sweet sorghum cultivars grown for biofuel. Field Crops Research, Amsterdam, v. 111, p. 55-64, 2009.

DOI: $10.1016 /$ j.fcr.2008.10.006.

WANG, M. L.; ZHU, C.; BARKLEY, N. A.; CHEN, Z.; ERPELDING, J. E.; MURRAY, S. C.; TUINSTRA, M. R.; PEDERSON, G. A.; YU, J. Genetic diversity and population structure analysis of accessions in the US historic sweet sorghum collection. Theoretical and Applied Genetics, v. 120, n. 1, p. 13-23, 2009.

DOI: $10.1007 / \mathrm{s} 00122-009-1155-6$. 